\title{
Efficiency in milk production on Reunion Island: Dealing with land scarcity
}

\author{
M. D’Haese,${ }^{*} \dagger^{1}$ S. Speelman, ${ }^{*}$ V. Alary, $\ddagger$ E. Tillard, $\S$ and L. D’Haese ${ }^{*}$ \\ *Department of Agricultural Economics, Ghent University, 9000 Ghent, Belgium \\ †Development Economics Group, Wageningen University, 6706 KN Wageningen, the Netherlands \\ $\ddagger$ Centre de cooperation international en recherché agronomique pour le développement (CIRAD), UPR Livestock Systems and Animal Product \\ Management, 34398 Montpellier Cedex 5, France \\ $\S C I R A D$, UMR Ruminant Husbandry in Warm Regions, 97410 St. Pierre, Reunion Island, France \\ \#Department of Applied Biological Sciences, University of Antwerp, 2020 Antwerpen, Belgium
}

\section{ABSTRACT}

This paper aims to analyze efficiency on dairy farms in Reunion Island, a French overseas district located in the Indian Ocean. On this island, dairy farming is promoted with financial and technical support from the European Union, with the French and local governments aiming at reducing dependency on imports of milk powder and dairy products and creating employment. A critical factor for increasing the local milk production is the limited availability of arable land because of the small size and the volcanic nature of the island. In this paper, we study the efficiency levels of dairy production on 34 farms by using a data envelopment analysis approach. The average technical efficiency score of farms, assuming constant returns to scale, was 0.927 , with 19 out of 34 farms not being efficient. The technical efficiency with a variable returns to scale specification was 0.951 . The efficiency with which farmers used their land (subvector efficiencies) was estimated in a second model. The average subvector efficiencies calculated with constant returns to scale and variable returns to scale models were lower than the technical efficiencies. The farmers on the efficiency frontier had a relatively higher milk production, milk production per cow, and land surface than those who were less efficient. A policy promoting better use of the land on inefficient farms should increase the milk production-to-land ratio. Possible on-farm strategies are improved feeding systems, farms having their own heifer breeding, and improved genetics.

Key words: milk production, efficiency analysis, Reunion Island

\section{INTRODUCTION}

Reunion Island is a French overseas department located in the tropics, approximately $800 \mathrm{~km}$ east of

Received November 7, 2008.

Accepted March 23, 2009.

${ }^{1}$ Corresponding author: marijke.dhaese@ugent.be the coast of Madagascar, in the Indian Ocean. Because of the scarcity of agricultural land and the hilly landscape, the potential for agricultural activities is limited. The economy of the island once depended on sugarcane plantations, the derived products of which are still the main agricultural export. Today's economy thrives on tourism and services (BBC, 2007). In the early 1960s, local dairy production was begun on Reunion Island. Three main factors have since contributed to the growth of the dairy sector, namely, 1) a well-organized local dairy chain; 2) financial and technical support of the French and local governments and the European Union for establishing farms in hilly areas, covering initial investment costs in dairy farm equipment; and 3) the mobilization of a group of highly motivated farmers interested in dairy farming (Alary et al., 2008). Despite the continued governmental support, steady growth in milk production, and unsatisfied demand from the local processing sector for local fresh milk, the local dairy sector faces an uncertain future because of area limitations and environmental risks. Because of increased urban pressure, land is particularly scarce on the small and volcanic island. The purpose of this paper was therefore to study the potential of the dairy sector to respond to increasing demands for fresh milk produced on the island by increasing the production efficiency. Special attention was paid to the potential gains in efficiency of land use.

In 1962, SICA-Lait, a cooperative of dairy farmers, was created (Louhichi et al., 2004; Institut d'Emission des Departement d'Outre-Mer, 2006). The SICA-Lait cooperative devoted its activities to the collection of milk and the provision of material and technical support to dairy farmers (Louhichi et al., 2004). Almost all milk produced on the island is collected by this cooperative. Over the last several years, the number of dairy farms has decreased, but the total number of milking cows, and hence local milk production, has increased. The milk collected and bulked by SICA-Lait is sold to Compagnie Laitière des Mascareignes for processing into UHT bricks, yogurt, and cheese. Local milk is 
mixed with imported milk powder in the final products, except for the UHT milk brand Piton des Neiges and local cheeses, which are produced from local milk only. An estimated $75 \%$ of the milk and cheese products consumed on Reunion Island are imported.

The milk price paid to the farmers is fixed per liter by the interprofessional organization Association réunionnaise interprofessionnelle pour le bétail et les viandes (ARIBEV), which regroups all actors within the milk chain. (ARIBEV was created in 1975 for the beef, milk, and pork chain, and an interprofessional association for the poultry sector was begun in 1994.) The ARIBEV organization rallies representatives of the wholesalers, retailers, and importers. It provides a discussion forum, enables the enforcement of agreements throughout the chain, and defends the interests of its members. Furthermore, ARIBEV hosts the Fonds de Développement de l'Elevage Laitier, which was established in the 1980s as part of the Poseidom program, which is a European Union support program directed to French overseas departments. (Poseidom stands for "Programme d'options spécifiques à l'éloignement et à l'insularité des Départements d'outre-mer" or Programme of specific options to overcome the remote and isolated nature of French overseas departments.) The main activities of Fonds de Développement de l'Elevage Laitier are to support milk prices and to provide milk quality control and financial support for milk collection. In addition to the guaranteed fixed milk prices, farmers are also supported in several activities and investments [see Louhichi et al. (2004) for a detailed overview].

Regarding the price for fresh milk, it is worth mentioning that although the price paid to the dairy farmers does not depend on fat and protein content or on microbiological quality, contaminated milk is rejected by SICA-Lait. An extra payment is made periodically to farmers who consistently provide milk of good microbiological quality.

The total milk consumption [in milk equivalents, calculated as the sum of total imported (customs statistics) and locally produced milk and milk products] on the island averaged $137 \mathrm{~L}$ per capita in 2005, which is far below the level of $330 \mathrm{~L}$ per capita in mainland France (Centre National Interprofessionnel de l'Economie Laitière, 2005). The different actors in the supply chain consider that the dairy sector on Reunion Island has the potential to increase production far above the 20 million tons of milk currently produced. Moreover, the milk quota of 40 million tons (Louhichi et al., 2004) attributed to Reunion Island is far from being reached. A major aspect of increased demand for fresh milk is the current dependence of the processing and retail industry on imported milk powder and dairy products. The world market price for milk powder as well as transpor- tation costs has fluctuated during the last several years. For the industry to reduce its reliance on imports, the demand for fresh milk has increased. Given the limited land available for agriculture, however, it is unlikely that this demand for milk production could be satisfied by operating more farms.

To explore the potential for gains in efficiency, we calculated the technical and land use efficiency of the dairy farms on the island using a data envelopment analysis (DEA) approach. The model used data collected in the year 2000 for 34 farms. The DEA yields the relative efficiency levels of the farms. It calculates a frontier of efficient farms by assuming inputs to be optimally minimized for a given output level. Recently, Stokes et al. (2007) used a DEA model to study factors contributing to the efficiency in production and business management of dairy farmers in Pennsylvania. A DEA approach to calculate the efficiency of dairy farming was also used by Piesse et al. (1996), Jaforullah and Whiteman (1999), Mbaga et al. (2003), Balcombe et al. (2006), and Hansson (2007). Although these studies considered a multiple-input production system, they did not analyze subvector efficiencies of one specific input. Subvector efficiency measures are introduced to generate technical efficiency measures for a subset of inputs rather than for the entire vector of inputs. We used this extension of the DEA model to analyze the importance of land as a key input. The subvector efficiency of land use provides an indication of the relative efficiency with which farmers use land and, consequently, of the scope for improvements in land use efficiency.

\section{MATERIALS AND METHODS}

\section{Technical and Subvector Efficiency}

We used measures for technical efficiency that originated from the seminal work of Farrell (1957). Technical efficiency was defined by Farrell (1957) in 2 ways, namely, 1) the ability of a farm to produce the maximum feasible output with a given bundle of inputs; or 2) the ability of a farm to use minimum inputs to produce a given level of output. These 2 definitions of technical efficiency lead to what is known as the output-oriented and the input-oriented efficiency measure, respectively (Coelli et al., 2002; Dhungana et al., 2004; Rodríguez Díaz et al., 2004). In this study, we assumed an inputoriented model, which enabled us to calculate subvector efficiency scores for a subset of inputs, rather than for the entire vector of inputs (Färe et al., 1994; Oude Lansink et al., 2002; Oude Lansink and Silva, 2004). We were interested in the subvector efficiency of land use. The subvector efficiency reflects a possible reduction in land use, keeping the levels of all other inputs and outputs constant. 


\section{Principles of DEA and Subvector Efficiency Estimation}

The DEA is based on the notion that a production unit is more efficient when using fewer inputs to produce the same amount of output. The most efficient farms (with an efficiency score of 1) are on a production frontier. These farms use a minimum set of inputs to produce a given level of output. The frontier is assembled piecewise by solving a sequence of linear programming problems, one for each farm. Subsequently, by relating each farm to the frontier, efficiency scores are calculated for the other farms. In this way, the frontier envelops the observed input and output data of all farms.

To express the model mathematically, we consider a theoretical data set of $K$ inputs and $M$ outputs for $N$ farms. For farm $i$, input and output data are represented by the column vectors $\mathbf{x}_{\mathbf{i}}$ and $\mathbf{y}_{\mathbf{i}}$, respectively. The $\mathbf{K}$ by $\mathbf{N}$ input matrix $X$ and the $\mathbf{M}$ by $\mathbf{N}$ output matrix $Y$ represent the data for all $N$ farms in the sample. The DEA model used to calculate the technical efficiency is given by equation [1], namely,

$$
\operatorname{Min}_{\theta \lambda} \theta,
$$

subject to $-y_{i}+Y \lambda \geq 0, \theta x_{i}-X \lambda \geq 0, N 1^{\prime} \lambda=0$, and $\lambda \geq 0$, with $\theta$ being a scalar, $N 1$ being an $\mathbf{N}$ by $\mathbf{1}$ vector of ones, and $\lambda$ being an $\mathbf{N}$ by $\mathbf{1}$ vector of constants. Using the variables $\lambda$ and $\theta$, the model is solved once for each farm, looking for the largest radial contraction of the input vector $x_{i}$ within the technology set. The first constraint ensures that output produced by the $i$ th farm will be smaller than that on the frontier. The second constraint limits the proportional decrease in input use when $\theta$ is minimized, to the input use achieved with the best observed technology. Constraint 3 is a convexity constraint by which the model is in a variable returns to scale (VRS) specification (Speelman et al., 2008). Without the convexity constraint, equation [1] makes up the constant returns to scale (CRS) specification. In the CRS specification, it is assumed that farms are operating at their optimal scale (Fraser and Cordina, 1999), whereas under VRS the scale explains part of the inefficiency. Comparison of the scores from both specifications expresses the scale efficiency at which a farm operates.

The second efficiency measure used in this paper is the subvector efficiency for land use. Following Färe et al. (1994), the technical subvector efficiency for the variable input $k$ is determined for each farm $i$ by solving the following programming problem (equation [2]):

$$
\operatorname{Min}_{\theta \lambda} \theta^{k}
$$

subject to $-y_{i}+Y \lambda \geq 0, \theta^{k} x_{i}^{k}-X^{k} \lambda \geq 0, x_{i}^{n-k}-X^{n-k} \lambda \geq 0$, $N 1^{\prime} \lambda=1$, and $\lambda \geq 0$, where $\theta^{k}$ is the input $k$ subvector efficiency score for farm $i$. The terms $x_{i}^{n-k}$ and $X^{n-k}$ in the third constraint refer to input $x_{i}$ and the matrix $X$ with the input $k$ (column) excluded, whereas in the second constraint, the terms $x_{i}^{k}$ and $X^{k}$ include only the input $k$. All other variables are defined as in equation [1].

Figure 1 illustrates how technical efficiency and subvector efficiency scores are calculated in a DEA model for farm A that is inefficiently using land and labor relative to its peers on the efficiency frontier (in the example determined by farms F1 and F2). The model searches for the maximal inward radial movement of input vector $x_{i}$ of farm $\mathrm{A}$ (which is how much land and labor farm A uses) while staying within the feasible input set. The inner boundary of this set is a piecewise linear isoquant determined by the frontier data points (the efficient farms in the sample are F1 and F2). The radial contraction of the input vector $x_{i}$ determines the position of a projected point on the frontier surface $\left(A^{0}\right)$. This projected point is a linear combination of the observed data points, with the constraints in equation [1] and ensuring that the projected point is within the feasible set. The technical efficiency score of farm A relative to the frontier is given by the ratio $\theta=$ $0 A^{0} / 0 A$.

The subvector efficiency score with which farm A uses land is calculated by reducing land use and holding labor use and the level of milk produced constant. $A^{\prime}$ is the projection of $A$, and the subvector efficiency is given by the ratio $\theta^{1}=0^{\prime} A^{\prime} / 0^{\prime} A$.

In this study, the CRS and the VRS DEA models for technical efficiency (equation [1]) were estimated using the Data Envelopment Analysis Program (Coelli, 1996). Subvector efficiencies (equation [2]) were modeled in the General Algebraic Modeling System using the methodology proposed by Färe et al. (1994). In the results section, the average technical efficiency scores are reported and the farms on the efficiency frontier are compared with farms that are not efficient. We also compare technical efficiency scores in CRS and VRS specifications and subvector efficiency scores.

\section{Data}

Detailed data on 34 dairy farms were collected in 2000. The sample covered $20 \%$ of the entire dairy farm population. The sample was compiled by experts to be representative of the different farming systems on Reunion Island with their variety in initial endowment (including land, debts and initial capital, and subsidies), 
Labor

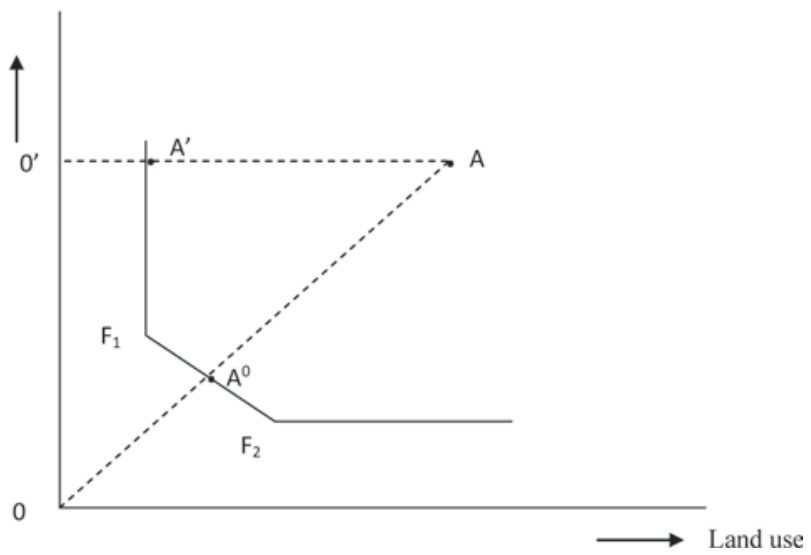

Figure 1. Graphical representation of the measurement of technical efficiency and subvector efficiency using data envelopment analysis for an example with 2 inputs (land use and labor) and 1 output (milk production).

livestock and pasture management, local agroclimatic constraints, and personal objectives of the farmers. The farms to be analyzed were therefore initially chosen to reflect between-herd variability to represent the diversity in dimensions (including land endowments, herd, and milk production) on Reunion Island (Alary et al., 2002; Alary and SICA-Lait, 2004). A detailed account of the sampling procedure can be found in Alary and SICA-Lait (2004).

As mentioned, these data were used in a DEA model to calculate the levels of technical efficiency. A critical issue in DEA is the choice of the relevant input and output variables. We chose the production of milk in liters as the output in the model, which was the most obvious choice because farmers are paid per liter produced. Unlike in the studies of Stokes et al. (2007),
Mbaga et al. (2003), and Jaforullah and Whiteman (1999), the content of milk fat was not included as an output because it did not influence the revenue of the farmers. We did not consider as a second output the bonus for consistency in quality paid to those farmers who kept the microbiological milk quality constant. This bonus for quality is paid periodically, making it difficult to obtain reliable data on a yearly basis. Furthermore, experts consider that up to $95 \%$ of the farmers on Reunion Island meet the minimal quality standards.

The inputs considered for this study were herd size, land endowment (hectares), active labor on the farm (given in full-time equivalents), costs for livestock (including disease control, feeding, and reproduction), and operational costs of the farm (these are recurrent costs such as water, electricity, fuel, maintenance, insurance, management, and other costs).

Table 1 describes the main characteristics of the farms in the sample. Farms had on average 36 cows, of which 29 were in lactation (Table 1). Their mean surface area was 16.6 ha; the size of the smallest farm in the sample was 1 ha and that of the largest farm was 73 ha. They employed on average 2 full-time persons. The youngest farmer was 25 years old; the average age of the farmer in our sample was 40 years. Several farmers had received a professional degree, whereas some had a degree at the superior level.

The descriptors in Table 1 and, in particular, the standard deviations show that the sample reflected the large diversity of farms on the island, also in terms of size. (The large variety among the farms could create outlier problems if the data were analyzed using regression analyses. However, the DEA methodology compares relative efficiency levels, which can be scale independent if scale economies are absent.) Although

Table 1. Overview of output, inputs used, and farmer characteristics $(\mathrm{n}=34)$

\begin{tabular}{lcccc}
\hline Item & Mean & SD & Minimum & Maximum \\
\hline Milk production, L & 177,252 & 108,394 & 22,094 & 529,721 \\
Milk production per cow, L/cow & 4,693 & 1,288 & 1,105 & 7,440 \\
Cows, n & 36.1 & 16.6 & 11.0 & 86.0 \\
Cows in lactation, n & 29.0 & 14.9 & 9.0 & 73.0 \\
Land, ha & 16.6 & 15.8 & 1.0 & 73.0 \\
Labor, FTE & 2.4 & 0.9 & 1.0 & 4.6 \\
Costs for livestock, euros & 48,906 & 30,438 & 4,369 & 153,568 \\
Operational costs, euros & 15,064 & 10,477 & 2,188 & 45,518 \\
Altitude of farm, m above sea level & 1,018 & 396 & 300 & 1,700 \\
Farmer characteristic & & & & \\
Age of farmer, yr & 40.0 & & & \\
Education level, \% of total & & & & \\
$\quad$ Primary degree & 26.5 & & & \\
$\quad$ Secondary degree & 23.5 & & & \\
Professional degree & 32.4 & & & \\
$\quad$ Superior level & 17.6 & & & \\
\hline
\end{tabular}

${ }^{1} \mathrm{FTE}=$ full-time equivalents. 
the data set represented $20 \%$ of the total dairy farms on the island, drawing general conclusions for all dairy farmers on the island with this relatively small data set was difficult.

To illustrate the precision of the results of this study, we calculated the optimal sample size that would have been needed to estimate the milk production per cow with $10 \%$ accuracy at a $95 \%$ confidence level. The standard deviation of milk production per cow in lactation was 2,027.9, and the mean was 6,091.9 l (an accuracy level of $10 \%$ implies that deviation from the mean of 6,001 was accepted). With the formulas given in De Pelsmacker and Van Kenhove (2002), the minimal sample size corrected for a finite population of 150 dairy farms would be 33.9 , or 34 farms, which was exactly covered by our sample size. The calculation was done as follows: the formula presented in De Pelsmacker and Van Kenhove (2002) for calculating the minimal sample size $\mathrm{n}$ was $\mathrm{n}=[(\mathrm{z}$-value of the normal distribution at a $95 \%$ confidence level $\left.)^{2} \times(\mathrm{SD})^{2}\right] /[($ sampling error or accuracy level as deviation from the mean accepted $\left.)^{2}\right]$ $=\left[(1.96)^{2} \times(2027.9)^{2}\right] /(600)^{2}=43.8$. The $\mathrm{n}$ is adjusted for the finite population $(\mathrm{N})$ with the formula $\mathrm{n}^{\prime}=\mathrm{n} /(1$ $+\mathrm{n} / \mathrm{N})=43.8 /(1+43.8 / 150)=33.9$.

\section{RESULTS AND DISCUSSION}

A DEA model is a nonparametric approach to calculate efficiency scores. Alternatively, efficiency scores can be calculated with a parametric model; the stochastic frontier production function approach is the most popular parametric technique [see also Mbaga et al. (2003) and Balcombe et al. (2006)]. The DEA methodology has some important advantages over the parametric approach for measuring efficiency. First, because DEA is a nonparametric approach, there is no need to make assumptions concerning the functional form of the frontier technology or the distribution of the inefficiency term. Second, DEA permits a frontier of efficient farms in the data to be distinguished, which allows the comparison of one production method with the others in terms of a performance index. The DEA allows the efficiency gap to be calculated that separates the behavior of each producer from the best productive practices, which can be assessed from actual observations of the inputs and outputs of efficient firms (Wadud and White, 2000; Haji, 2006). Third, efficiency measures are not affected significantly by small sample size in a DEA as long as the number of inputs is not high in comparison with the sample size (Thiam et al., 2001). Finally, the DEA approach allows subvector efficiencies to be calculated. Oude Lansink et al. (2002) argued that calculating subvector efficiencies using a stochastic frontier approach would be highly problematic.
The disadvantages of DEA are its deterministic nature and its sensitivity to measurement errors and other noise in the data. Nevertheless, comparative studies have shown that efficiency scores generated by both methods are highly correlated (Wadud and White, 2000; Thiam et al., 2001). Balcombe et al. (2006) concluded that for studies that wish to identify farms operating at lower levels of technical efficiency, as in this study, the choice of estimation methodology seems to be less an issue. However, the appropriate choice of frontier model is problematic when the study aims at comparing the relative level of technical efficiency (Balcombe et al., 2006).

The set of inputs considered in this study was comparable with those of Piesse et al. (1996), who used land (hectares), capital (dinars), and labor (workforce hours), and of Stokes et al. (2007), who introduced land (hectares), labor (full-time equivalents), cows, and debt $(\$)$ in their model. Expenditure on feed or feed production (namely, one or more of the following: forage, concentrates, fertilizer, seeds, and others) was also used by Hansson (2007), Balcombe et al. (2006), Mbaga et al. (2003), and Jaforullah and Whiteman (1999). Expenditure on animal health and herd testing was considered as an input by Jaforullah and Whiteman (1999).

A higher average technical efficiency was obtained in the VRS specification compared with the CRS estimates (Table 2). This suggests that not all farms operated on an efficient scale. The scale efficiency, which is the ratio between the CRS and VRS efficiency level for each farm, measures the potential productivity gains from operating at an optimal scale. Higher VRS efficiencies suggest that adjusting the scale will improve the efficiency. The average score for subvector efficiencies of the farms in the sample was lower than the average technical efficiency estimated, again with the average CRS subvector efficiency being lower than the VRS subvector estimates. The results for subvector efficiency of the land revealed that relative inefficiencies in land use were larger.

The group of technically inefficient (CRS specification) farms consisted of 19 cases; the technical efficiency scores of those farms were on average 0.869 , with a standard deviation of 0.087 . The subvector efficiency of land use for these farms averaged 0.474, with a standard deviation of 0.262 . These figures confirm that the relative high technical efficiency scores masked a degree of inefficiency in the use of land (Figure 2). The inefficient farmers in the sample seem to be able to compensate for the less efficient use of land by a better use of other inputs.

Efficient farms (we consider here farms on the CRS technical frontier) in the sample had higher milk production $(P<0.05)$, a greater number of cows in lacta- 


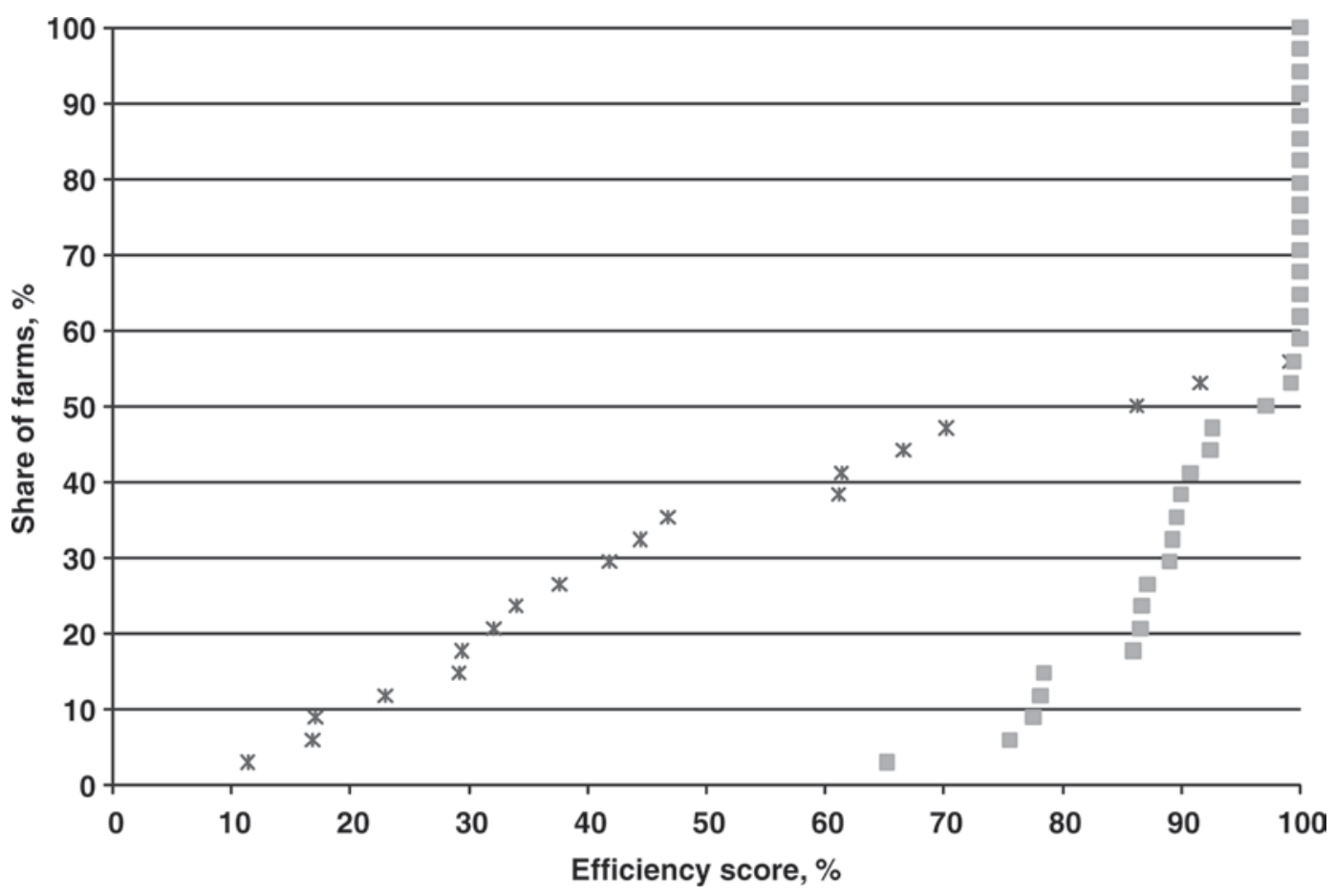

Figure 2. Efficiency scores by share of farmers. Squares are technical efficiency scores and stars are subvector efficiency scores.

tion $(P<0.10)$, and a higher level of livestock costs $(P<0.10)$ than inefficient farms (results of the MannWhitney tests reported in Table 3). Efficient farms in the sample also performed significantly better in milk production per cow $(P<0.05)$. The averages for herd size, land, labor input, and operational costs were also higher for efficient farms, yet differences from inefficient farms were not statistically significant. Farmers of both groups were not statistically different in age, the altitudes of the farms did not differ, and no statistical evidence was found to suggest that farmers' education levels were different between the 2 groups. It is worth mentioning that the CRS technical efficiency frontier was given by the same farms as for the CRS subvector technical efficiency frontier.

In an analysis of dairy farms in Pennsylvania, Stokes et al. (2007) concluded that inefficient farms seemed to overuse labor and overinvest in land in combination with having lower levels of milk production. When economic inputs were taken into account, an overuse of debt was found to be problematic for inefficient farms (Stokes et al., 2007). Obviously, it is difficult to compare farms in different geographical (hence biological) conditions.

In the case of the farms analyzed in this paper, higher technical efficiency was related to higher milk production, including when expressed per cow. Furthermore, efficient farms in the sample seemed to have larger herds and more spending on disease control, feeding, and reproduction. This result validates what had been previously identified as better performing farmer groups on Reunion Island (Louhichi et al., 2004). From the 6 groups identified by those authors, the groups with the highest milk production per animal were either small farms with small herd sizes on limited land or larger farms with larger herds and a large degree of capitalization.

Given the scarcity of land, producing more milk with a constant number of cows raised on the limited available land would have a larger positive (economic and environmental) impact than increasing the number of

Table 2. Summary of results of technical data envelopment analysis with subvector efficiency for land in use in constant returns to scale $(\mathrm{CRS})$ and variable returns to scale (VRS; $\mathrm{n}=34$ )

\begin{tabular}{lcccc}
\hline Item & Mean & SD & Minimum & Maximum \\
\hline Technical efficiency CRS & 0.927 & 0.092 & 0.653 & 1.000 \\
Technical efficiency VRS & 0.951 & 0.072 & 0.730 & 1.000 \\
Subvector efficiency CRS & 0.706 & 0.328 & 0.114 & 1.000 \\
Subvector efficiency VRS & 0.811 & 0.270 & 0.178 & 1.000 \\
\hline
\end{tabular}


Table 3. Comparison of technically efficient constant returns to scale (CRS) and less technical efficient CRS farmers ${ }^{1}$

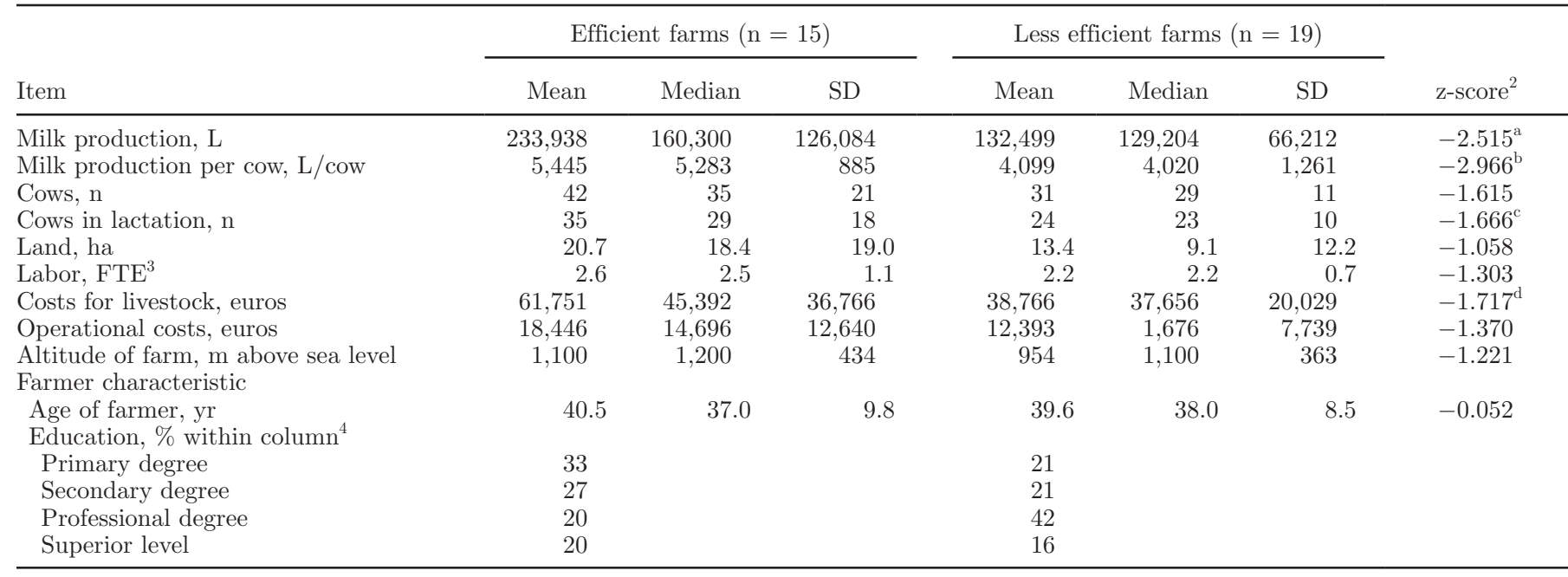

${ }^{\mathrm{a}, \mathrm{b}}$ Medians within a row differ $(P<0.05)$.

${ }^{\mathrm{c}, \mathrm{d}}$ Medians within a row differ $(P<0.10)$.

${ }^{1}$ Farms with a technical CRS score of 1 were considered efficient (on the data envelopment analysis frontier), whereas those with a technical CRS score below 1 were considered less efficient.

${ }^{2}$ To compare the means of continuous variables, a nonparametric Mann-Whitney test was run.

${ }^{3} \mathrm{FTE}=$ full-time equivalents.

${ }^{4}$ The relationship between the degree of education and the farm being efficient or not was checked with a chi-squared test. The chi-squared statistic was 1.940 and was not statistically significant.

cows per hectare. Suggestions given by Louhichi et al. (2004) for investing in improvements on the farm were improved feeding systems, on-farm heifer breeding, and improved genetics (proposed only for the larger farms). We also expected that investing in an improvement of the farms' own fodder production and optimizing the use of concentrates would contribute significantly toward increasing the technical efficiency and guaranteeing the sustainability of milk production, especially in the context of fluctuating prices of raw inputs on the international markets. Other specific suggestions for on-farm development were to increase the age of culling and of removing the oldest cows, to improve the preventive control of infectious and metabolic diseases, and in general, to improve husbandry practices by training famers to improve their technical skills.

\section{CONCLUSIONS}

The results of the efficiency analysis of our sample showed 3 main points: 1) inefficient farms were not operating at the optimal scale of production; 2) the average technical efficiency was better than the average subvector efficiency for the use of land; and 3) efficient farms seemed to be larger in terms of herd size, operational costs, and milk production. The results suggest that dairy production on Reunion Island had potential areas of efficiency gains, especially when more was invested to increase milk production on a given land area. Given the current land scarcity, it is more probable that a sustainable local dairy sector should be developed with the current number of cows on the land that is now in use by dairy farmers. It is unlikely that more land will become available to dairy farmers, except if farmers can access land that is currently used for other crops (e.g., sugarcane). For some scale-inefficient farmers, merging with other farms could be beneficial. However, the institutional implications of such a policy were not analyzed in this paper.

Policy initiatives could be taken to train farmers, with the aim of enhancing their technical efficiency by improving general animal husbandry practices, on-farm fodder production, and the use of concentrate feeds. First, however, more research is needed to develop such new production systems, especially to adapt these to the special climatic conditions of Reunion Island.

The success of such on-farm improvements for the local dairy sector will depend on the macroeconomic context of the dairy industry on the island. This economic environment will depend on the development of the local demand for fresh milk and the expectations of subsidies and other support schemes of the European Union, French, and local governments. Issues that influence the local demand for fresh milk include, among others, consumers' willingness to pay for local milk compared with dairy products that are imported 
or processed from milk powder, future developments in the international milk market and its impact on the price of milk powder, and the evolution of international prices of transport and inputs. These are areas for future research. In this paper, we did not study environmental issues, such as manure disposal, which deserve attention in follow-up studies, given the strict European regulations and the scarcity of land.

\section{ACKNOWLEDGMENTS}

The authors thank the dairy cooperative SICA-Lait, the dairy processor CILAM, the statistical service (INSEE), and the dairy farmers of Reunion Island for their kind help during this research.

\section{REFERENCES}

Alary, V., M. Gousseff, and U. B. Nidumolu. 2008. Comparison of multi-criteria decision models to approach the trade-off between environmental sustainability and economical viability - A case of nitrogen balance in dairy farming systems in Reunion Island. J. Agric. Sci. 146:389-402.

Alary, V., S. Messad, C. Taché, and E. Tillard. 2002. Approche de la diversité des systèmes d'élevage latiers à la Réunion. Rev. Elev. Med. Vet. Pays Trop. 55:285-297.

Alary V., and SICA-Lait. 2004. Modélisation des systèmes d'exploitation laitière à la Réunion. Montpellier, Cirad-emvt/Opération ELE 105. Pôle Elevage La Réunion, Saint-Pierre, France.

Balcombe, K., I. Fraser, and J. H. Kim. 2006. Estimating technical efficiency of Australian dairy farms using alternative frontier methodologies. Appl. Econ. 38:2221-2236.

BBC. 2007. Regions and territories: Reunion. http://news.bbc.co.uk/2/ hi/africa/country_profiles/4469169.stm Accessed Nov. 20, 2007.

Centre National Interprofessionnel de l'Economie Laitière. 2005. Home page. http://www.maison-du-lait.com/QuiFait/OrgInter/CNIEL/ cniel.html Accessed July 15, 2007.

Coelli, T. 1996. A guide to DEAP Version 2: A data envelopment analysis (computer) program. Working Papers. Centre for Efficiency and Productivity Analysis (CEPA), ed. University of New England, Armidale, Australia.

Coelli, T., S. Rahman, and C. Thirtle. 2002. Technical, allocative, cost and scale efficiencies in Bangladesh rice cultivation: A nonparametric approach. J. Agric. Econ. 53:607-627.

De Pelsmacker, P., and P. Van Kenhove. 2002. Marktonderzoek, methoden en toepassingen.Marketing research, methods and applications (in Dutch). 4th ed. Garant Uitgevers, Antwerpen, Belgium.
Dhungana, B. R., P. I. Nuthall, and G. V. Nartea. 2004. Measuring the economic inefficiency of Nepalese rice farms using data envelopment analysis. Aust. J. Agric. Resour. Econ. 48:347-369.

Färe, R., S. Grosskopf, and C. A. K. Lovel. 1994. Production Frontiers. Cambridge University Press, Cambridge, UK.

Farrell, M. J. 1957. The measurement of productive efficiency. J. R. Stat. Soc., Ser. A 120:253-281.

Fraser, I., and D. Cordina. 1999. An application of data envelopment analysis to irrigated dairy farms in Northern Victoria, Australia. Agric. Syst. 59:267-282

Haji, J. 2006. Production efficiency of smallholders' vegetabledominated mixed farming system in Eastern Ethiopia: A nonparametric approach. J. Afr. Econ. 16:1-27.

Hansson, H. 2007. Strategy factors as drivers and restraints on dairy farm performance: Evidence from Sweden. Agric. Syst. 94:726737.

Institut d'Emission des Departement d'Outre-Mer. 2006. La Réunion en 2005. Institut d'Emission des Departement d'Outre-Mer, Paris, France.

Jaforullah, M., and J. Whiteman. 1999. Scale efficiency in the New Zealand dairy industry: A non-parametric approach. Aust. J. Agric. Resour. Econ. 43:523-541.

Louhichi, K., V. Alary, and P. Grimaud. 2004. A dynamic model to analyse the bio-technical and socio-economic interaction in dairy farming systems on the Réunion Island. Anim. Res. 53:363-382.

Mbaga, M. D., R. Romain, B. Larue, and L. Lebel. 2003. Assessing technical efficiency of Québec dairy farms. Can. J. Agric. Econ. $51: 121-137$.

Oude Lansink, A., K. Pietola, and S. Bäckman. 2002. Efficiency and productivity of conventional and organic farms in Finland 19941997. Eur. Rev. Agric. Econ. 29:51-65.

Oude Lansink, A., and E. Silva. 2004. Non-parametric production analysis of pesticide use in the Netherlands. J. Productiv. Anal. 21:49-65.

Piesse, J., C. Thirtle, and J. Turk. 1996. Efficiency and ownership of Slovene dairying: A comparison of econometric and programming techniques. J. Comp. Econ. 22:1-22.

Rodríguez Díaz, J. A., E. Camacho Poyato, and R. López Luque. 2004. Application of data envelopment analysis to studies of irrigation efficiency in Andalusia. J. Irrig. Drain. Eng. 130:175-183.

Speelman, S., M. D'Haese, J. Buysse, and L. D'Haese. 2008. A measure for the efficiency of water use and its determinants, study at smallscale irrigation schemes in North-West Province, South Africa. Agric. Sys. 98:31-39.

Stokes, J. R., P. R. Tozer, and J. Hyde. 2007. Identifying efficient dairy producers using data envelopment analysis. J. Dairy Sci. 90:2555-2562.

Thiam, A., B. E. Bravo-Ureta, and T. E. Rivas. 2001. Technical efficiency in developing country agriculture: A meta analysis. Agric. Econ. 25:235-243.

Wadud, A., and B. White. 2000. Farm household efficiency in Bangladesh: A comparison of stochastic frontier and DEA methods. Appl. Econ. 35:1665-1673. 